\title{
Synergistic Behavior of Graphene and Ionic Liquid as Bio-Based Lubricant Additive
}

\author{
Muhammad Harith Hasnul ${ }^{1, *}$, Nurin Wahidah Mohd Zulkifli ${ }^{1}$, Masjuki Hassan ${ }^{2}$, Syahir Amzar Zulkifli ${ }^{1}$, \\ Mohd Nur Ashraf Mohd Yusoff ${ }^{1}$ and Muhammad Zulfattah Zakaria ${ }^{1}$ \\ 1 Department of Mechanical Engineering, Faculty of Engineering, University of Malaya, \\ Kuala Lumpur 50603, Malaysia; nurinmz@um.edu.my (N.W.M.Z.); syahiramzar@gmail.com (S.A.Z.); \\ ashraf.yusoff@yahoo.com (M.N.A.M.Y.); zulfattah@utem.edu.my (M.Z.Z.) \\ 2 Department of Mechanical Engineering, Faculty of Engineering, International Islamic University Malaysia, \\ Kuala Lumpur 53100, Malaysia; masjuki@iium.edu.my \\ * Correspondence: hasnulharith@gmail.com
}

Citation: Hasnul, M.H.; Mohd Zulkifli, N.W.; Hassan, M.; Zulkifli, S.A.; Mohd Yusoff, M.N.A.; Zakaria, M.Z. Synergistic Behavior of Graphene and Ionic Liquid as BioBased Lubricant Additive. Lubricants 2021, 9, 46. https://doi.org/10.3390/ lubricants 9050046

Received: 28 February 2021

Accepted: 21 April 2021

Published: 24 April 2021

Publisher's Note: MDPI stays neutral with regard to jurisdictional claims in published maps and institutional affiliations.

Copyright: (C) 2021 by the authors. Licensee MDPI, Basel, Switzerland. This article is an open access article distributed under the terms and conditions of the Creative Commons Attribution (CC BY) license (https:// creativecommons.org/licenses/by/ $4.0 /)$.

\begin{abstract}
The constant utilization of petroleum-based products has prompted concerns about the environment, hence a replacement for these products must be explored. Biolubricants are a suitable replacement for petroleum-based lubricants as they provide better lubricity. Biolubricant performance can be improved by the addition of graphene. However, there are reports that graphene is unable to form a stable suspension for a long period. This study used a graphene-ionic liquid additive combination to stabilize the dispersion in a biolubricant. Graphene and ionic liquid were dispersed into the biolubricant via a magnetic stirrer. The samples were tested using a high frequency reciprocating rig. The cast iron sample was then further observed using various techniques to determine the lubricating mechanism of the lubricant. Different dispersion stability of graphene was observed for different biolubricants, which can be improved with ionic liquids. All ionic liquid samples maintained an absorbance value of three for one month. The utilization of ionic liquid was also able to decrease the frictional performance by 33\%. Further study showed that by using the ionic liquid alone, the frictional could only reduce the friction coefficient by $13 \%$ and graphene could only reduce the friction by $7 \%$. A smooth worn surface scar can be seen on the graphene-IL sample compared to the prominent corrosive spot on the IL samples and abrasive scars on graphene samples. This indicates synergistic behavior between the two additives. It was found that the ionic liquid does not only improve the dispersion stability, but also plays a role in forming the tribolayer.
\end{abstract}

Keywords: biolubricant; graphene; ionic liquid; friction and wear

\section{Introduction}

Our dependency of petroleum-based products is now in to the spotlight as there is increasing environmental awareness and concerns regarding the health of the environment. Further dependency on these products may lead to foreseeable consequences as they are toxic, non-renewable, and harmful to the environment [1]. Hence, an alternative must be found to these types of products. Bio-based lubricants are a possible substitute to petroleum-based lubricants as they have good lubricity, high flash point, high viscosity index, and good resistance to shear compared to mineral oils [2]. Bio-based lubricants are lubricants derived from bio-based raw materials, which makes them renewable and environmentally-friendly [3].

Despite their advantages, the widespread usage of bio-based lubricants today is still limited due to major challenges concerning their performance, production scale, and lack of encouragement from the authorities. Henceforth, the reliability of bio-based lubricants must be strengthened in order to promote the bio-lubricant usage. By introducing suitable additives, it is possible to improve the performance of bio-based lubricants [4]. 
Graphene is a carbon allotrope that has the potential to be utilized in many application such as hydrogen storage [5], supercapacitors [6], hydrogen sensing [7], energy storage [8-11], and enhanced electromagnetic interface shielding [12]. Graphene is also a suitable additive to improve the tribological properties of bio-lubricants. The excellent thermal [13] and mechanical properties of graphene, along with its unique two-dimensional structure, enable further friction and wear reduction by the bio-lubricant. Demirtas and Kaleli [14] tested the performance of graphene in actual piston ring-cylinder liner working condition and found that the graphene was readily able form a protective layer, hence increasing the tribological performance. Zulkifli and Azman [15] have found that graphene can improve the tribological properties of palm-based Trimethylolpropane (TMP) ester blended with Polyalphaolefin (PAO). The concentration of graphene in a bio-based oil must also be within the optimum range as too little graphene will form an incomplete lubricating film and too much will reduce its effectiveness to reduce friction [16].

However, the inertness of graphene has hindered its ability to form a uniform dispersion after a long period of time. This concern was met with various studies to improve the dispersion stability of graphene such as structure modification and using surfactant. An extensive study by Zhang and $\mathrm{Xu}$ [17] found that graphene oxide cannot be dispersed in rapeseed oil on its own and the unstable dispersion can have a detrimental effect on its tribological properties. Dou and Koltonow [18] also proved the importance of dispersion stability where they successfully synthesized a self-dispersed graphene that improved the dispersion stability and significantly improved the friction and wear performance.

One of the ways to improve the dispersion stability of graphene is by modifying its chemical structure. The graphene structure can be combined with other chemical structures via chemical structure. A previous study modified graphene using octadecylamine and dicyclohexylcarbodiimide [19], alkyl structure [20], and a titanate coupling agent [21]. Another method is by adding surfactants, which are an easier solution. Sarno and Cirillo [22] were able to stabilize various carbon allotropes just by adding Tween 80 as a surfactant, which also resulted in increased friction and wear reduction.

This study focused on countering the unstable graphene dispersion using an ionic liquid (IL) as a surfactant for the lubricant. Ionic liquid is molten salt at room temperature that consists of an anion and cation. Previous studies have highlighted the ability of ionic liquid as a friction modifier additive to lubricants. However, the polar nature of ionic liquid can interact with graphene to form a stable dispersion, which makes it a suitable surfactant for graphene. This means that it is possible that the addition of ionic liquid to a graphene dispersion can stabilize the dispersion while further increasing the tribological behavior of the lubricant. This study focuses on the synergistic effect between graphene and ionic liquid, which will be analyzed in terms of dispersion stability, frictional behavior, and wear mechanism.

\section{Materials and Methods}

Three base oils and two additives were used in this study. For the base oil, the three mentioned base oils were polyol esters (i.e., neopentyl glycol dioleate (NPG), trimethylol propane trioleate (TMP), and pentaerythritol tetraoleate (PE)). All base oils were purchased from Shandong Ruijie Chemical Industry Co. Limited., Qingdao, China. The two additives selected were graphene as the tribological additive and ionic liquid, which was initially selected as the surfactant. Graphene nanoplatelets were purchased from the Low Dimensional Material Research Center, University of Malaya, Kuala Lumpur, Malaysia. Information regarding graphene properties was given by the supplier. The field emission scanning electron microscope (FESEM) image along with energy dispersive X-ray (EDX) analysis of the graphene nanoplatelet is shown in Figure 1 and Table 1 displays the given graphene properties. The ionic liquid selected was trihexyltetradecylphosphonium bis(2,4,4-trimethylpentyl)phosphinate. Ionic liquid is purchased from IoLiTec-Ionic Liquids Technologies GmbH, Heilbronn, Deutschland. 


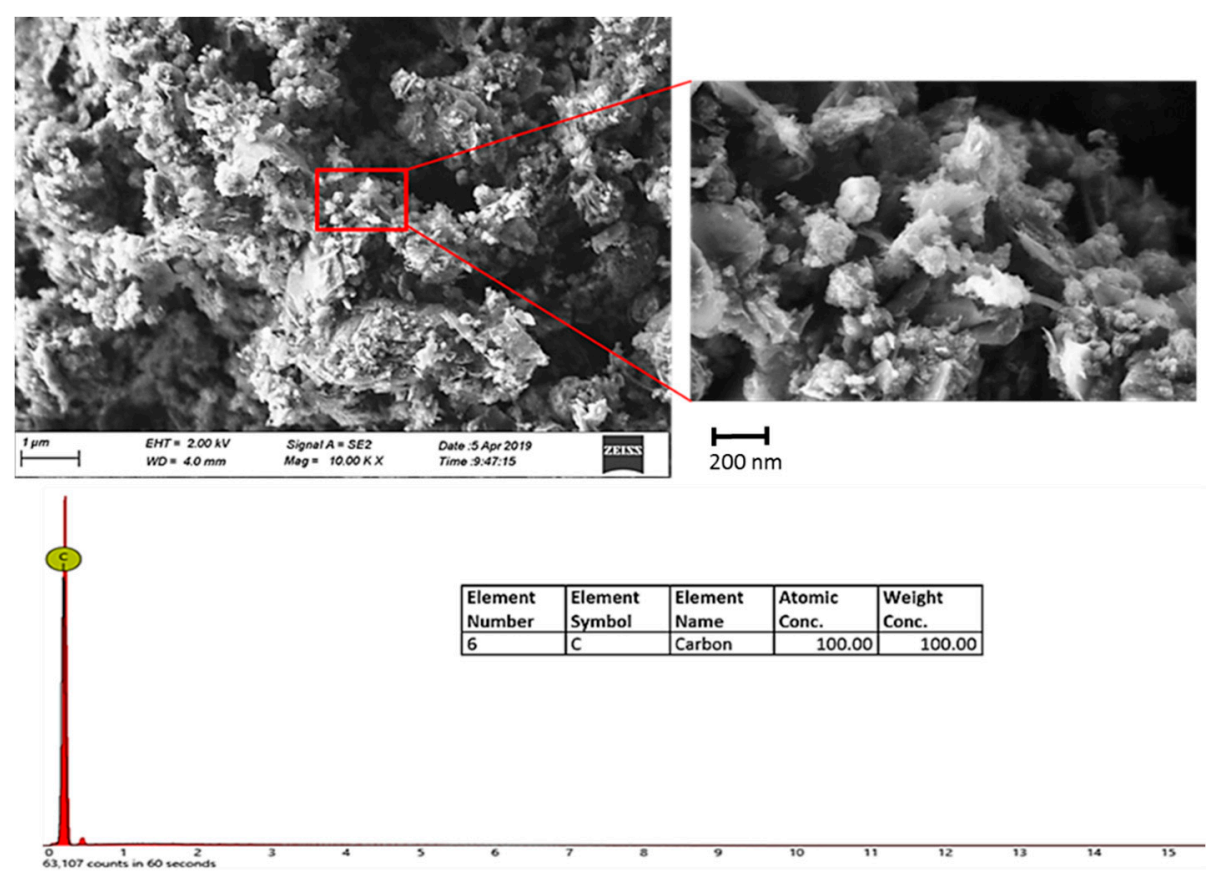

Figure 1. FESEM micrograph focusing on graphene and EDX spectrum on graphene nanoplatelet.

Table 1. Properties of the graphene nanoplatelet.

\begin{tabular}{cc}
\hline Name & Graphene Nanoplatelet \\
\hline Appearance (Form) & Powder \\
Appearance (Color) & Black \\
Purity (\%)* & 99 \\
Morphology * & Non-spherical, multilayer \\
Thickness * & $\sim 5 \mathrm{~nm}$ \\
Surface area * & $120 \mathrm{~m}^{2} / \mathrm{g}$ \\
\hline
\end{tabular}

${ }^{*}$ Data provided by the manufacturer.

Graphene nanoplatelets were dispersed in three separate bio-based oils by stirring with a magnet for $2 \mathrm{~h}$ at $80{ }^{\circ} \mathrm{C}$ and $700 \mathrm{rpm}$. The bio-based oils selected were the neopentylglycol (NPG) ester, trimethylolpropane (TMP) ester, and pentaerythritol (PE) ester. Graphene was blended at a concentration of $0.1 \mathrm{wt} \%$. Ionic liquid was then added to the blend at $1 \mathrm{wt}$. \% to all blends. The ionic liquid used was trihexyltetradecylphosphonium bis(2,4,4-trimethylpentyl)phosphinate. Chemical structures for all base oils and ionic liquid are shown in Figure 2.

The sample containing ionic liquid will then be compared with the pure graphene dispersion in term of their dispersion stability using the sedimentation test and UV-Vis spectrophotometer. The samples were observed for one month. The viscosity index, viscosity, and density of the samples were also compared by using a SVM3000 Stabinger Viscometer (Anton Paar GmbH, Graz, Austria) according to ASTM 445. In terms of tribological behavior, samples were tested using a high frequency reciprocating rig (HFRR). The contact was a line contact between a stainless steel pin to a grey cast iron plate. Grey cast iron plate was obtained commercially, which was cut into $15 \times 15 \mathrm{~mm}$ using a wire cutting machine. The plates were polished using a surface grinder machine to obtain an approximate surface roughness of 1-1.2 $\mu \mathrm{m}$. Stainless steel roller bearings were also purchased commercially with a diameter of $6 \mathrm{~mm}$. The sample was cut to a length of $6 \mathrm{~mm}$. The samples were submerged with the lubricant before starting the HFRR testing. The working parameter and operating condition for testing is shown in Figure 3 and Table 2. After testing, both the plate and the pin were changed before testing the next samples. Three tests per sample were done to ensure reproducibility. 


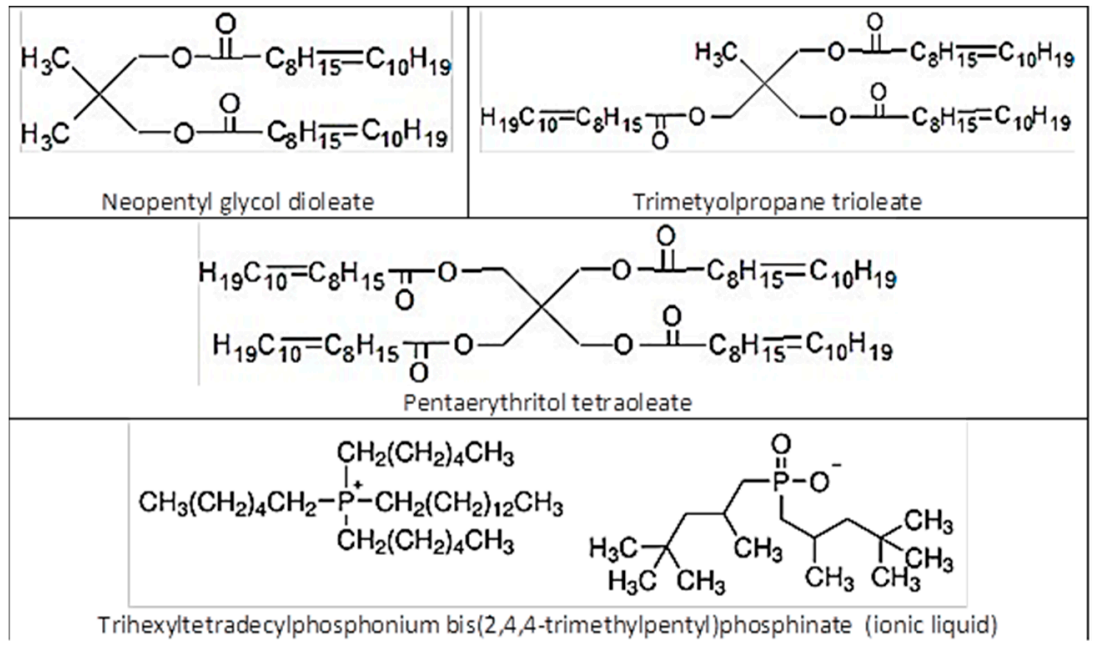

Figure 2. Chemical structure of material used in the study.

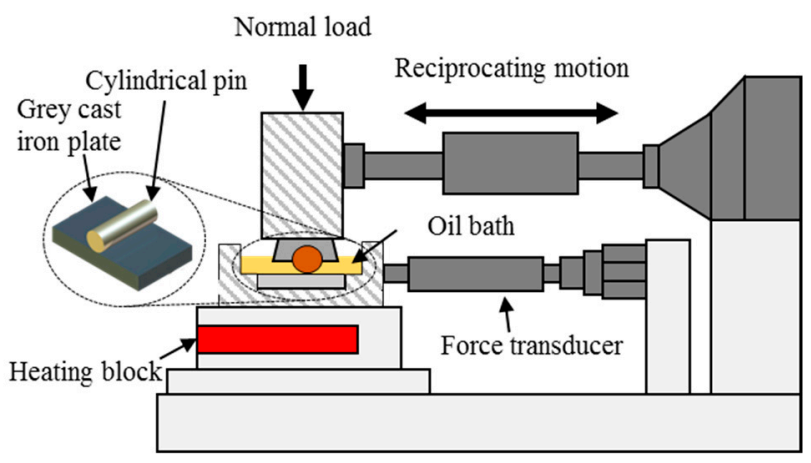

Figure 3. Schematic diagram of HFRR testing.

Table 2. Operating condition of HFRR testing.

\begin{tabular}{cc}
\hline Parameter & Value \\
\hline Duration & $3600 \mathrm{~s} / 1 \mathrm{~h}$ \\
Frequency & $10 \mathrm{~Hz}$ \\
Temperature & $75^{\circ} \mathrm{C}$ \\
Load & $100 \mathrm{~N}$ \\
Stroke length & $5 \mathrm{~mm}$ \\
\hline
\end{tabular}

The wear scar from the cast iron plate was then analyzed under scanning electron microscopy (SEM), energy dispersive x-ray spectroscopy (EDX), surface profilometer, and Raman spectroscopy to study the wear mechanism of the IL contained graphene dispersion. SEM was done to observe the worn scar surface whereas the surface profilometer was used to obtain 3D imaging and measure the surface roughness. EDX and Raman spectroscopy helped in confirming the synergy between the graphene and ionic liquid.

\section{Results and Discussion}

\subsection{Physicochemical Properties of Lubricant Samples}

From Table 3, it can be seen that the addition of graphene only caused minor changes in viscosity and density. A more notable change could be seen in after the ionic liquid was added into the samples. However, the change was not significant enough to change the lubrication regime between all samples. The lack of change in the graphene sample can be attributed to its low concentration. A study by Azman and Zulkifli [23] confirms that the 
addition of graphene in low concentration (0.01-0.5 wt $\%)$ does not significantly change the physicochemical properties of the PAO-TMP blend.

Table 3. Physicochemical properties of the lubricant samples.

\begin{tabular}{ccccc}
\hline Samples & $\begin{array}{c}\text { Kinematic } \\
\text { Viscosity } @ \mathbf{4 0}{ }^{\circ} \mathbf{C}\end{array}$ & $\begin{array}{c}\text { Kinematic } \\
\text { Viscosity @ } \mathbf{1 0 0}{ }^{\circ} \mathbf{C}\end{array}$ & Viscosity Index & Density \\
\hline Pure NPG & 26.086 & 6.3539 & 210.8 & 0.9084 \\
NPG + G & 26.217 & 6.3612 & 209.7 & 0.9080 \\
NPG + G + IL & 27.568 & 6.6109 & 209.9 & 0.9100 \\
Pure TMP & 48.447 & 9.648 & 188.9 & 0.9196 \\
TMP + G & 49.312 & 9.7751 & 188.6 & 0.9198 \\
TMP + G + IL & 51.814 & 9.9973 & 183.8 & 0.9200 \\
Pure PE & 63.407 & 11.855 & 186.1 & 0.9295 \\
PE + G & 63.216 & 11.815 & 185.8 & 0.9295 \\
PE + G + IL & 65.366 & 11.886 & 178.9 & 0.9298 \\
\hline
\end{tabular}

It was observed that samples with different base oils exhibited noteworthy different viscosity value while maintaining an almost similar density. This difference can be explained by relating it with each molecular size. Viscosity by definition is the resistance to flow, hence in this case, NPG, which has a lower molecular size (as can be seen in Figure 2) will have a higher tendency to flow, and therefore a lower viscosity. Since the chemical structure of fatty acid is the same for all base oils, viscosity increased with higher molecular weight and size [24].

\subsection{Dispersion Stability of Graphene-IL in Bio-Based Lubricant}

As seen in Figure 4, graphene dispersion was observed for over one month using a UVVis spectrophotometer. The absorbance value by the UV-Vis spectrophotometer indicates the stability of graphene dispersion over time. For all samples, stable dispersion could be seen after one week (absorbance value of three). The dispersion started to destabilize after two weeks for both the TMP and NPG samples with NPG being more apparent. Meanwhile, almost all samples started to sediment at the third week. It can be seen that NPG and TMP exhibited similar absorbance at the third week, however, TMP was able to retain a more stable dispersion after one month. Graphene dispersed in PE ester had a more stable dispersion compared to other samples. Samples with IL exhibited better dispersion stability, which means that an IL has the capability to act as a dispersing agent for graphene in all base oils.

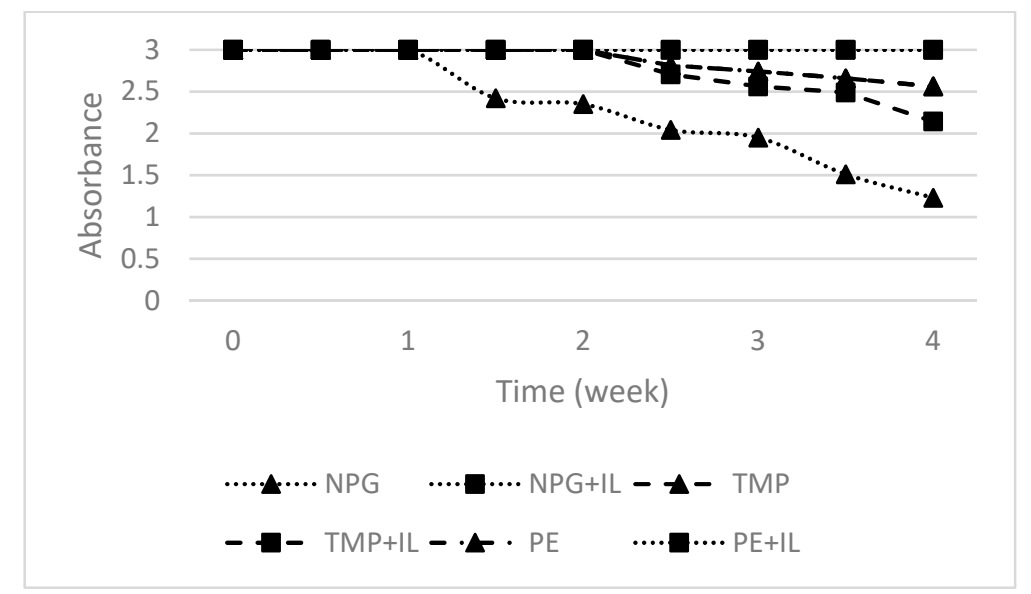

Figure 4. UV-Vis spectrophotometer for graphene-IL samples for one month.

To compare the different base oils, it was seen that NPG has a significant drop in dispersion stability after one month. This was followed by TMP, while PE was shown to 
have good dispersion stability even without the presence of an additive. The difference in dispersion stability between the base oils can be explained by the presence of carbon number on the molecular structure, which leads to less polarity.

It can be seen that the presence of IL increased the stability of the graphene dispersion. Ionic liquid can easily disperse graphene and is able to provide a more stable dispersion to the samples. This can be supported by a study by Zhang and Ning [25], where graphene oxide is able to form a stable colloidal suspension without the aid of a surfactant/dispersant in pure ionic liquid. In this case, the ionic liquid improves the graphene dispersion by being the mediator between graphene and the bio-based oil to form a more uniform dispersion. Contrary to the assumed "cation- $\pi$ " interaction, Wang and Chu [26] found that the high dielectric constant from the IL could shield the strong " $\pi-\pi$ " stacking interaction by the carbon allotrope, hence effectively dispersing the nanoparticles. The reduced dispersion stability with respect to time occurred due to the agglomeration of graphene where the nanoparticles lump together and form a sedimentation layer.

\subsection{Tribological Behavior of IL-Graphene Contained Lubricant}

Frictional trend can be explained by analyzing the running-in period, which is the initial period and the steady-state period where the frictional trend settles down. The addition of graphene and ionic liquid is able to decrease the friction in thee steady-state period for the PE and TMP samples. PE $+\mathrm{G}$ was able to reduce the overall friction by having a more stable frictional trend compared to the base PE. PE + G + IL exhibited a similar decrease in friction, however, it had a second spike in friction during the running-in period, which lengthened the running-in period. This is caused by very high friction during the initial contact and instability of the initial protective layer formation. However, $\mathrm{PE}+\mathrm{G}+\mathrm{IL}$ is able to achieve overall lower friction by having a substantially lower friction during the steady-state period.

Frictional trend of the TMP samples are shown in Figure 5b. TMP + G + IL was able to reduce the overall frictional performance by significantly reducing the friction during both the running-in and steady state period, however, the base TMP was seen to have a smoother running-in to steady-state transition. TMP $+\mathrm{G}$ exhibited higher friction and longer time in the running-in period, but it achieved lower overall friction due to its lower steady-state friction when compared to the base TMP.
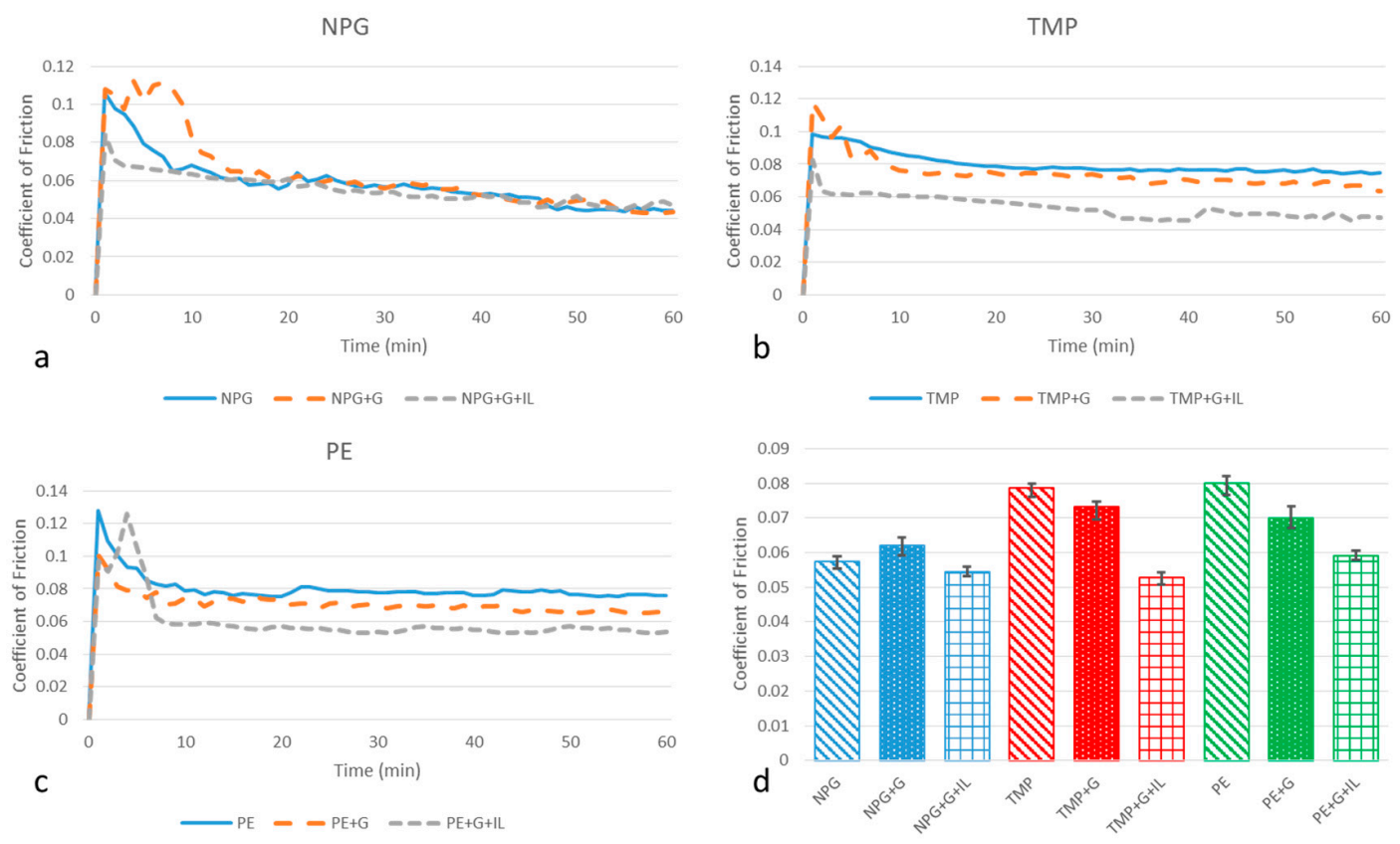

Figure 5. Frictional trends for (a) NPG samples, (b) TMP samples, and (c) PE samples along with (d) average coefficient of friction for all samples. 
From Figure 5a, it can be seen that the NPG samples showed a similar trend during the steady-state period where the frictional trend stabilized and steadily decreased until the end of testing. However, the different frictional behaviors during their running-in period severely affected the overall frictional performance. NPG $+\mathrm{G}+\mathrm{IL}$ was able to reduce the frictional magnitude during initial contact and swiftly transition to its steady-state period compared to its base oil. The disruptive running-in performance by NPG $+\mathrm{G}$ increased the friction and lengthened the running-in period, resulting in higher overall friction.

The average coefficient of friction is shown in Figure $5 \mathrm{~d}$. The values were the average of the friction obtained throughout the experiment including the steady state and runningin period. The error bars in this bar chart indicates the highest and the lowest friction coefficient obtained from the test samples. From this graph, it was found that the presence of the ionic liquid not only improved the dispersion stability of the lubricant sample, but also improved the tribological performance. Ionic liquid, which is used as a surfactant, is a proven anti-wear additive. Lhermerout and Diederichs [27] attributed the ionic liquid promising tribological behavior to its ability to form a structured boundary tribofilm strongly bonded to polar or charged surfaced. Sanes and Avilés [28] found that there was a synergy when both IL and graphene were used whereby IL will form a protective layer for asperity contact and graphene will provide a protection layer on the wear track. It can be seen that samples with ionic liquid exhibited a similar average coefficient of friction around $0.052-0.059$. This is the result of a decrease in friction value in the steady-state period, as seen in Figure 5. This indicates the strengthening of the tribofilm, hence lowering friction.

It can be seen that TMP + G benefited the most from the addition of IL with a further decrease of $27 \%$ in the coefficient of friction. Hence, TMP samples will be used to further study the synergy between graphene and ionic liquid. The drastic change in its frictional performance allows a clearer view on the improvement by the graphene-IL additive combination.

\subsection{Synergy between Graphene and Ionic Liquid in Bio-Based Lubricant}

Both graphene dispersion and tribological behavior showed significant improvement for the all bio-based lubricants by graphene-IL. However, a question must be asked on whether this significant improvement comes from the incredible performance of the ionic liquid alone or if there is a synergy between graphene and ionic liquid that allows further improvement of the tribological performance of the biolubricant. Hence, the combination of TMP + IL must also be tested under the same condition.

Figure 6 shows the frictional performance of all TMP ester samples. It can be seen that the addition of $1 \mathrm{wt} \%$ ionic liquid had an effect on the tribological performance of the TMP ester. In particular, the ionic liquid used, trihexyl(tetradecyl)phosphonium bis $(2,4,4-$ trimethylpentyl)phosphinate (or $\left[\mathrm{P}_{14,6,6,6}\right][\mathrm{TMPP}]$ ), had good tribological properties due to the fact that it is halogen-free [29] and it is a phosphonium-phosphate ionic liquid [30]. However, the improvement was not as significant as TMP + G + IL. This indicates that the combination of graphene and ionic liquid improved more than the cumulative improvement of using graphene and ionic liquid alone. The significant improvement by $\mathrm{TMP}+\mathrm{G}+\mathrm{IL}$ signifies the presence of synergistic behavior between graphene and the ionic liquid. To look at it more objectively, TMP + G, TMP + IL, and TMP + G + IL achieved an overall friction reduction by $7 \%, 13 \%$, and 33\%, respectively, when compared to the TMP ester. The error bars in Figure $6 \mathrm{~b}$ indicate the highest and lowest coefficient of friction obtained from the test samples. An interesting point to note is that the highest friction of $\mathrm{TMP}+\mathrm{IL}$ and the lowest friction TMP + G resulted in a similar value. However, overall, there was a distinction in performance when using the two individual additives. This also highlights the significant improvement by TMP + G + IL. 

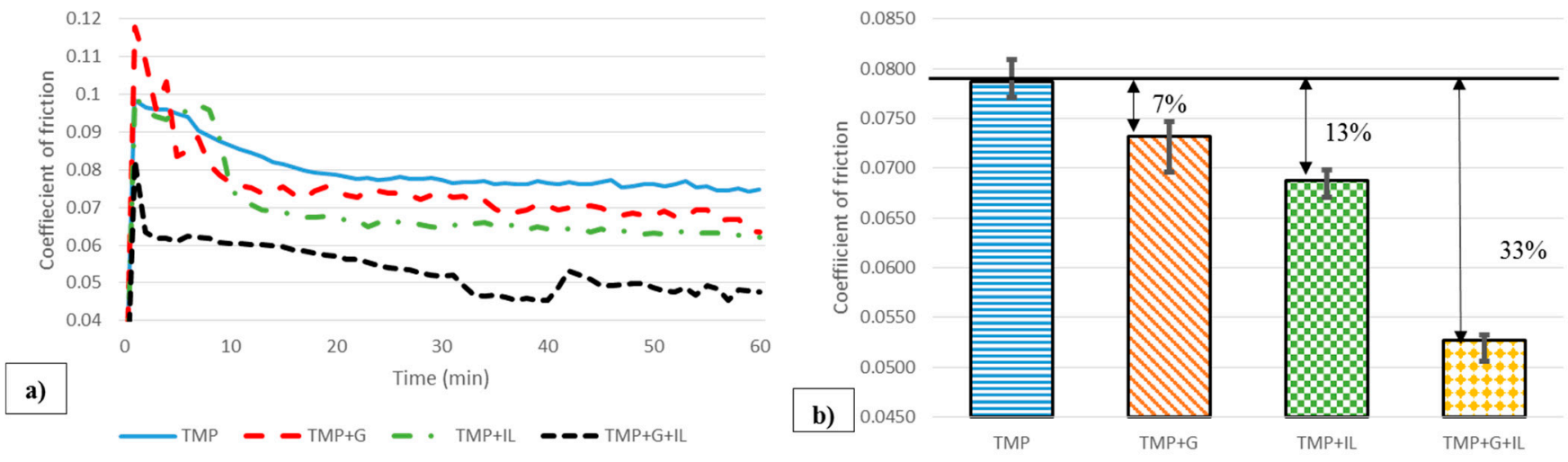

Figure 6. (a) Frictional performance of TMP samples and its (b) average coefficient of friction.

The synergistic behavior between ionic liquid and graphene can be clearly seen in its frictional performance from HFRR testing. With such a significant improvement compared to other samples, this synergy must be studied further. There are reported synergies between graphene and ionic liquid, however, it used a halogenic ionic liquid mixed in isoparaffinic oil and fully formulated oil [28]. The oil in which the ionic liquid and graphene disperse in is important as using different base oils will disturb the synergy between the two lubricant additives.

Although the frictional synergy between ionic liquid and graphene is proven, its antiwear performance is still untested. To achieve this, the cast iron samples used in the HFRR testing were observed using a surface profilometer to measure the surface roughness and scanning electron microscope to visualize the scar from the tribotest. This is important as the antiwear performance is crucial to ensure the synergy between the two additives does offer a significant trade-off to other critical lubricant properties.

Cast iron samples lubricated by TMP samples were observed under SEM and the result is shown in Figure 7. By only changing the additive composition, four different wear scars with different wear modes were observed. Plain TMP ester was seen to have many more abrasive scratches compared to the other samples.

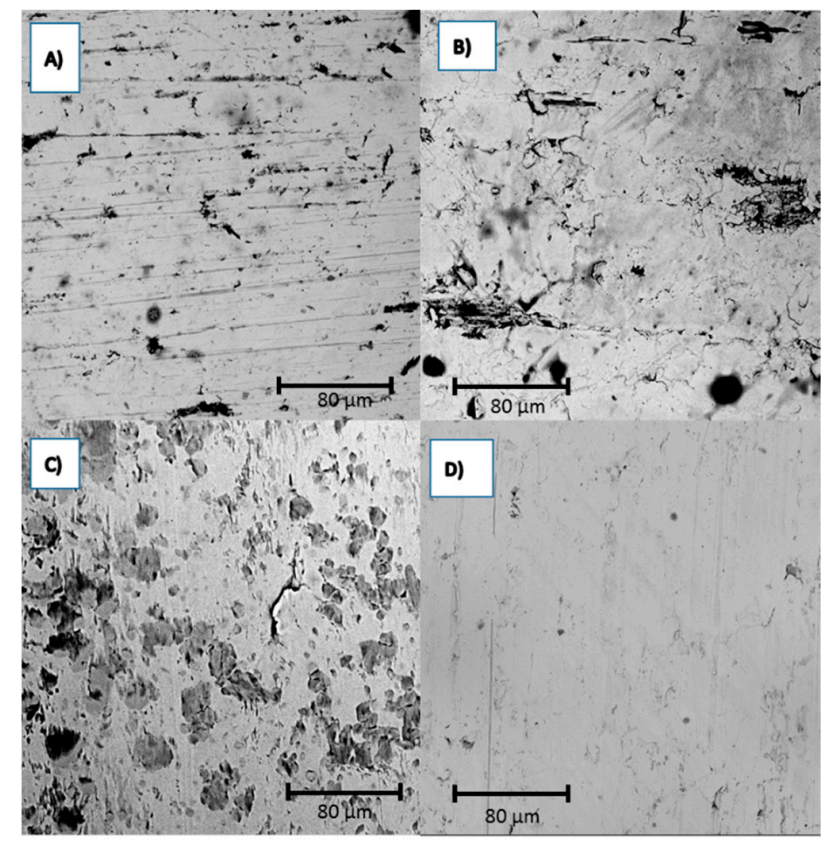

Figure 7. SEM images of the worn cast iron plate lubricated by (A) TMP, (B) TMP + G, (C)TMP + IL, and (D) TMP + G + IL samples. 
The addition of graphene in the TMP ester reduced the abrasive scratches that were prominent in the pure TMP sample. However, the wear mode shifted toward cracking and material removal (delamination). Severe material removal with moderate cracking is observed by graphene additives. Eswaraiah and Sankaranarayanan [31] also reported wear mode change to material removal by the addition of graphene in an engine oil. However, the study also reported that graphene reduced the wear scar area on the contacting area, indicating that graphene can improve wear reducing performance even though the wear mode has changed.

Unlike graphene, ionic liquid changes the wear mode to corrosion with minor cracking, though both reduced the abrasive scratches present in the pure TMP sample. The cracks on the ionic liquid sample were not as bad as those on the graphene sample, which was an improvement. However, the degree of corrosive wear of TMP + IL was too severe. The presence of corrosive attack can be due to the ionic liquid being a more reactive substance compared to the inert graphene. The presence of corrosive attack has been noted when using an ionic liquid as a lubricant additive, particularly in the TMP ester [29]. However, the utilization of an optimum ionic liquid concentration can defer the corrosive attack.

The most important thing to take note of is the combination of graphene and ionic liquid resulted in a much smoother wear compared to the other three samples. The abrasive scratches from the TMP ester is reduced significantly. This indicates that the tribofilm formed by TMP + G + IL is able to withstand the load during the experiment hence providing better protection for the contacting surfaces. On another note, there is no sign of corrosive attack and delamination in the sample as well. It can be inferred that the presence of graphene was able to diminish the corrosive attack of the ionic liquid. It is important to reduce the corrosive attack as the attack indicates unnatural acidic environment during testing. This mean that the synergy between the two additives is present. This is due to both additives having a different anti-wear mechanism from one another. Ionic liquid adsorb on to the contacting surface to prevent contact between asperities whereas graphene forms a protective layer on the contacting area [28]. Using this logic, the stronger tribofilm due to better film adsorption can reduce the delamination wear whereas the corrosive attack on the material can be prevented by graphene which is an inert material.

Three-dimensional (3D) surface topography for worn cast iron surfaces from HFRR tests are represented in Figure 8. Comparing to TMP ester, the surface roughness of the worn cast iron is significantly reduced by the addition of graphene $(\mathrm{Ra}=0.271 \mu \mathrm{m}$, $\mathrm{Rq}=0.472 \mu \mathrm{m}$ and $\mathrm{Rz}=1.568 \mu \mathrm{m}$ against $\mathrm{Ra}=0.853 \mu \mathrm{m}, \mathrm{Rq}=1.053 \mu \mathrm{m}$ and $\mathrm{Rz}=3.845 \mu \mathrm{m})$. This correlates with the frictional performance during the HFRR testing which indicates the successful formation of enhanced tribolayer. Ionic liquid also reduced the surface roughness with a value of $\mathrm{Ra}=0.162 \mu \mathrm{m}, \mathrm{Rq}=0.263 \mu \mathrm{m}$ and $\mathrm{Rz}=0.660 \mu \mathrm{m}$. It can be noted that the surface roughness of TMP ester with ionic liquid sample has lower surface roughness compared to graphene samples. However, this is attributed to the different wear modes between the samples. Since the delamination wear is more present in TMP $+\mathrm{G}$ sample, the surface roughness is higher due to the material removal creating a larger scar. Meanwhile, the lower surface roughness of TMP + IL sample is more prone to corrosive attacks.

The synergy between ionic liquid and graphene is clearly shown by measuring its surface roughness. When compared to base TMP ester, an almost $95 \%$ improvement on the surface roughness can be easily seen by using these two additives ( $\mathrm{Ra}=0.853 \mu \mathrm{m}$, $\mathrm{Rq}=1.053 \mu \mathrm{m}$ and $\mathrm{Rz}=3.845 \mu \mathrm{m}$ against $\mathrm{Ra}=0.042 \mu \mathrm{m}, \mathrm{Rq}=0.056 \mu \mathrm{m}$ and $\mathrm{Rz}=0.172 \mu \mathrm{m})$. This tremendous improvement can be expected from the frictional performance and the SEM images. The significant improvement on the frictional trend indicates a smoother operating condition hence less metal-to-metal contact can be assumed which reduces the wear between the surfaces. At the same time, the smoother wear mark seen in the SEM images indicates a more uniform surface in the wear area, hence the significantly lower surface roughness. 


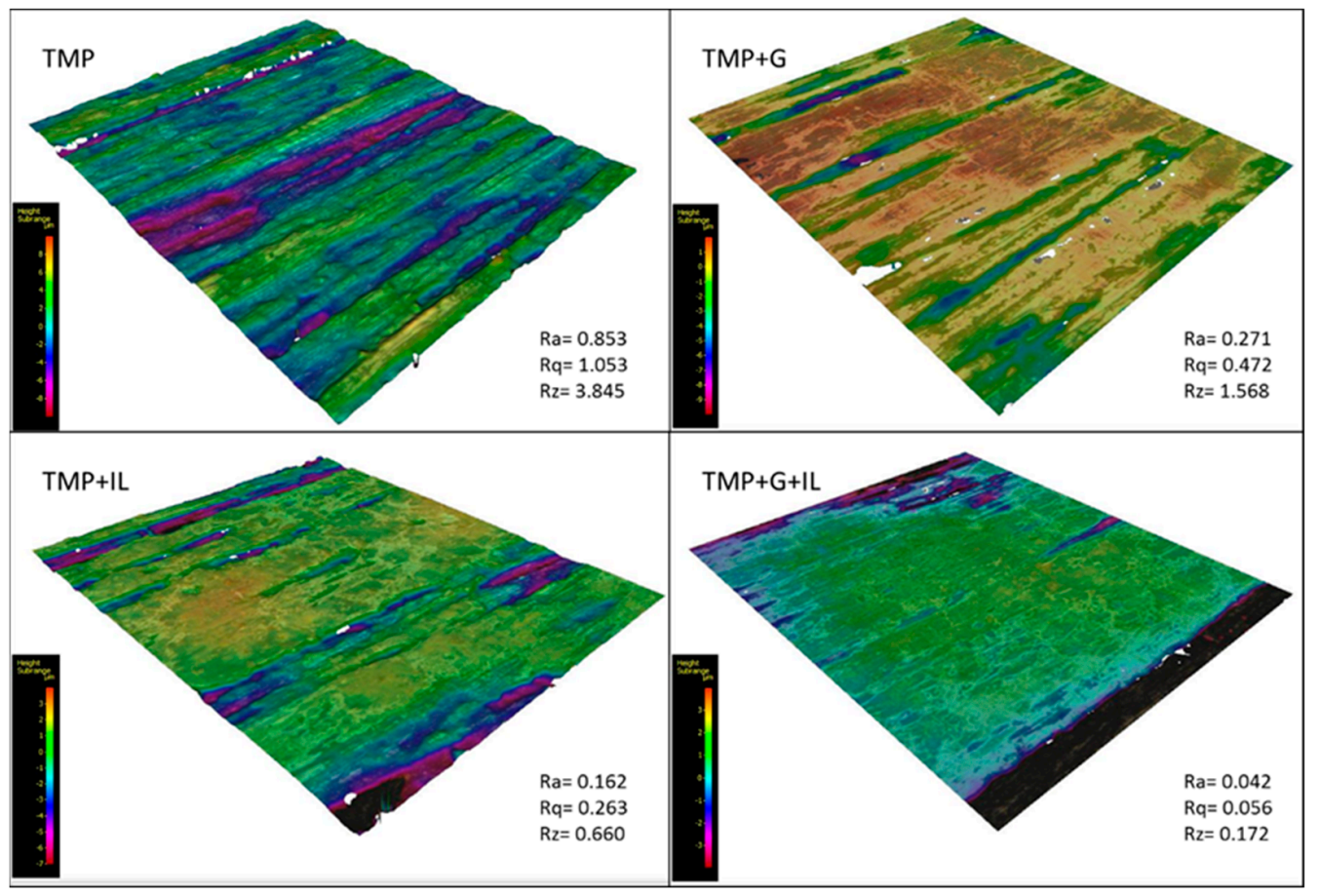

Figure 8. 3D topography of the worn cast iron surface.

With such excellent results in its frictional performance, wear, and surface roughness, the synergy between graphene and ionic liquid can be studied further, particularly regarding its tribofilm formation mechanism. By knowing its functionalities during the operating condition, a more in-depth knowledge can be obtained. To achieve this, energy dispersive $x$-ray spectroscopy (EDX) was used to investigate the elements found inside the wear scar and Raman spectroscopy obtained the binding energy on the worn surface. These two methods show how graphene and ionic liquid synergize with each other. Only TMP, TMP + G, and TMP + G + IL were analyzed as it was proven that the significant improvement was due to the synergies between the graphene-IL additive and not solely on IL. This will also make it easier to obtain knowledge on its mechanism.

From the EDX spectroscopy in Table 4, there were three prominent elements detected on the worn surface. The most common was iron $(\mathrm{Fe})$, which was due to the material of the cast iron plate. This element can be an indicator of the bare metal surface of the cast iron plate after the tribological test. The detected carbon element can also be attributed to the cast iron composition (usually contains more than $2 \%$ of carbon). However, the abundance of the carbon element can be due to the lubricated layer by the TMP ester, which is mostly made up of carbon due to its alkyl chain ( $\mathrm{C}-\mathrm{C}$ chain) and also graphene, which is completely made up of carbon. The oxygen can represent the oxide layer formation by the lubricant due to its tribochemistry reaction during the testing period.

Table 4. EDX spectroscopy on worn cast iron surface lubricated by TMP, TMP + G, and $\mathrm{TMP}+\mathrm{G}+\mathrm{IL}$.

\begin{tabular}{ccccc}
\hline Elements & Fe & C & O & P \\
\hline TMP & 89.36 & 6.32 & 2.51 & - \\
TMP + G & 75.71 & 15.45 & 8.83 & - \\
TMP + G + IL & 59.99 & 30.83 & 9.04 & 0.15 \\
\hline
\end{tabular}

When comparing the samples, there were some notable changes in the element composition going from TMP to TMP + G to TMP + G + IL. The first change was that the amount of elemental iron detected by EDX spectroscopy decreased from TMP to TMP + G + IL. 
This indicates that there was less exposed iron surface due to the presence of more additive, which also means a more effective protective film is formed by TMP + G and TMP + G + IL.

The next change was that the presence of elemental carbon was higher in TMP + G + IL, followed by TMP + G. The increase in elemental carbon was due to the utilization of graphene as an additive. Being completely made up of carbon atoms, the graphene tribolayer residue from the tribological testing increased the amount of carbon element. From another perspective, it can be seen that the carbon element from the TMP + G + IL sample was much higher than the TMP + G sample. This shows that the TMP + G + IL formed a more efficient graphene tribofilm compared to TMP + G due to better dispersibility of graphene in the sample (as can be seen in Figure 4), which translates to better graphene circulation to form a more effective tribofilm [32,33]. However, the increase in the amount of carbon can be attributed to the ionic liquid adsorbed in the metallic surface (ionic liquid mostly consisting of carbon element).

In term of oxygen detected on the worn surface, significant improvement can be seen with the addition of additives. However, there was minimal change between TMP + G and $\mathrm{TMP}+\mathrm{G}+\mathrm{IL}$, which indicates that the synergy between graphene and ionic liquid does not have a significant effect on the amount of elemental oxygen on the worn surfaces. In a study by Zulkifli and Azman [15], it was proposed that the TMP ester forms an oxidation layer on the worn surface, which acts as protection from metal-to-metal contact. If the amount of oxygen comes from the protective mechanism of the TMP ester, it can be said that the low amount of oxygen on the TMP sample was due to the tribolayer being solely dependent on the oxidation layer. This causes the oxidation layer to break down faster, unlike with the addition of the additive whereby graphene and the ionic liquid help the tribolayer, allowing more oxygen residue on the worn surface.

The final notable change was the presence of phosphorus on the worn surface of the TMP + G + IL alone. The ionic liquid selected in this experiment consisted of a phosphonium cation and phosphate anion in which both contain the phosphorus element. It can be noted the amount of phosphorus was quite low compared to the other elements, however, it is important nonetheless. This is because there are only two phosphorus elements in a single structure of the ionic liquid. The presence of phosphorus is important as it signifies that the ionic liquid not only helps in increasing the dispersion stability of graphene, but it also plays a part in reducing the frictional and wear performance of the lubricant.

Figure 9 shows the Raman spectroscopy of the worn surface. By utilizing the reading of the Raman spectrograph, it is possible to understand the lubricating mechanism of the lubricant samples, particularly the synergy between graphene and the ionic liquid. This technique uses the interaction between the laser light and the molecular vibrations, which results in an energy shift. This shift can be used to determine the vibration modes of the substances that reside on the worn surface. Significant peaks from the Raman shift are discussed with regard to how it can be interpreted with the support of EDX analysis done earlier.

When compared with the literature, inspection of the Raman spectrograph indicated the presence of $\mathrm{Fe}_{2} \mathrm{O}_{3}$ (iron(II) oxide) and $\mathrm{Fe}_{3} \mathrm{O}_{4}$ (iron(III) oxide). This is important as the formation of an oxide layer is important for the tribological performance of the lubricant and since the base metal is cast iron, iron oxide will represent that oxide layer. There was acceptable consistency for the highest Raman peak at $\sim 667, \sim 413, \sim 299$, and $\sim 225 \mathrm{~cm}^{-1}$ [34]. The Raman reading obtained from the sample, particularly in lower wavenumbers (100$800 \mathrm{~cm}^{-1}$ ), emitted a similar reading of hematite, a common iron oxide mineral. From this, some vibrational mode of iron oxide can be determined. $\mathrm{A}_{1 \mathrm{~g}}$ indicates the symmetric stretch of oxygen in Fe-O bonds, which can be represented by the 667 peak $\mathrm{cm}^{-1}$. $\mathrm{E}_{\mathrm{g}}$ and $\mathrm{T}_{2 \mathrm{~g}}$ showed both asymmetric and symmetric oxygen bonds with respect to iron, which was indicated by $413\left(\mathrm{E}_{\mathrm{g}}\right), 299\left(\mathrm{E}_{\mathrm{g}}\right)$, and $225\left(\mathrm{~T}_{2 \mathrm{~g}}\right) \mathrm{cm}^{-1}$ peaks. When the samples were compared, it could be seen that the four peaks that represent iron oxide could only be clearly seen in TMP + G and TMP $+G+$ IL whereas only two peaks were present in the 
TMP sample. Since the Raman spectrum indicates the presence of molecular bonds, it can be said that the $\mathrm{Fe}-\mathrm{O}$ was less in the TMP ester, which indicates a lower amount of oxide layer residue. As discussed previously, TMP samples solely rely on the oxide layer for the lubricating mechanism, hence the lower iron oxide layer. This is supported with the lower oxygen element count from the EDX analysis. With additives, other lubricating mechanism will be introduced, hence the presence of a higher amount of iron oxide.

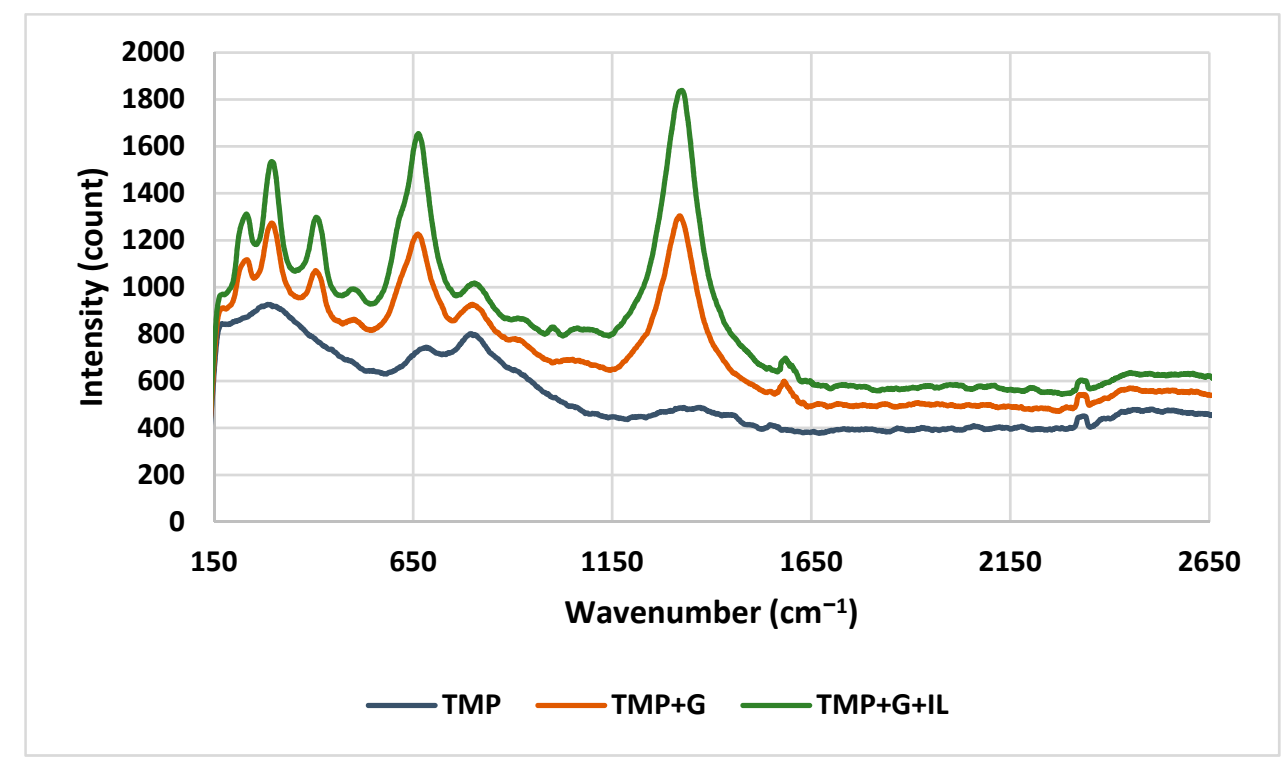

Figure 9. Raman spectra of the worn cast iron surface lubricated by TMP, TMP + G, and $\mathrm{TMP}+\mathrm{G}+\mathrm{IL}$.

Raman spectroscopy also confirmed that the improvement in tribological performance of TMP ester could be attributed to graphene entering the contacting surfaces and forming a deposition layer on the cast iron plate. In Figure 9, it can be seen that there was a Raman peak on $\sim 1320 \mathrm{~cm}^{-1}$ and $\sim 1585 \mathrm{~cm}^{-1}$, which signifies the D band and G band of graphene, respectively. Both of these are characteristic peaks that can be used to identify the presence of graphene. The $\mathrm{G}$ band exhibited due to the $\mathrm{E}_{2 \mathrm{~g}}$ phonon mode of the graphite symmetrical structure [35]. The $\mathrm{D}$ band, however, was caused by the structural disorder and defects in the $\mathrm{sp}^{2}$ hybridized material [36]. When compared between these two peaks, it can be clearly seen that the $\mathrm{I}_{\mathrm{D}} / \mathrm{I}_{\mathrm{G}}$ ratio was more than one, which indicates high structural damage in the graphene deposited on the worn cast iron plate. This damage in graphene structure can indicate that the deposited graphene layer acts as a sacrificial layer during the testing period to protect the contacting surfaces. It can also be seen that the intensity of the $\mathrm{D}$ band and G band was higher in the TMP + G + IL sample, indicating a higher amount of graphene deposited on the worn surface. This can be attributed to the higher supply of graphene due to better graphene dispersion.

There was one peak that was only exhibited in the Raman spectrum of TMP + G + IL at $\sim 1000 \mathrm{~cm}^{-1}$. When compared to the literature, a possible explanation is that the peak indicates $\mathrm{P}=\mathrm{O}$ stretching due to the utilization of a phosphonium ionic liquid [37]. Another peak that may arise due to the $\mathrm{P}=\mathrm{O}$ stretching is at $\sim 946 \mathrm{~cm}^{-1}$. However, both of these peaks were quite low in intensity, which indicates low traces of the phosphorus-oxygen bond. This is in line with the finding in the EDX analysis where low phosphorus count was detected on the worn surface.

From the results obtained, some lubricating mechanisms can be deduced, particularly when using TMP $+\mathrm{G}+\mathrm{IL}$ as it contains all of the lubricant sample components. The first important mechanism is the formation of an oxide layer due to the tribochemical reaction during the testing period. The higher temperature around the contacting area during the sliding motion promotes the in situ metal oxidation, hence forming the oxide 
layers [38]. This oxidation is further promoted due to the TMP ester having hydroxyl groups, which contain oxygen [29]. The lubricating mechanism can also be deduced. Graphene enters the contact area and forms a deposition layer that protects the sliding surfaces. This deposition layer will sacrifice itself in order to protect the contacting surface. The utilization of an ionic liquid as a surfactant allows for a higher dispersion of graphene in the base oil, therefore allowing a more uniform deposition layer that results in a more effective sacrificial layer. Ionic liquid also plays an important role in easing the friction and wear other than providing uniformity to graphene dispersion. Ionic liquid also forms a protective layer on the worn surface. However, the $\mathrm{P}=\mathrm{O}$ stretching band in the Raman spectrum indicates that the ionic liquid does not adsorb on the bare metal surface, but that it rather bonds with the oxygen from the oxidation layer. This will strengthen the oxide layer, hence providing secure protection of the contacting surface from wear.

\section{Conclusions}

The utilization of graphene and ionic liquid additives in bio-based lubricants has been studied in terms of its dispersion stability, tribological behavior, and its lubricating mechanism. The findings from this study can be summarized as follows:

- Only minor changes in the bio-based lubricant physical properties were observed after the addition of graphene and ionic liquid.

- The addition of the ionic liquid stabilizes the graphene suspension in the bio-based lubricant, hence increasing its dispersion stability.

- The combination of the graphene-IL additive exhibited superior tribological properties when compared to samples with the graphene additive alone.

- Though the ionic liquid alone can improve the frictional performance of the TMP ester, the improvement was as significant as TMP $+\mathrm{G}+\mathrm{IL}$, which indicates the presence of synergistic behavior between the two lubricant additives.

- Ionic liquid does not only allow a better supply of graphene in the contact area due to it higher dispersion stability, but it also plays a role in the TMP + G + IL lubricating mechanism.

Author Contributions: Conceptualization, M.H.H. and S.A.Z.; Methodology, M.H.H.; Validation, M.H.H., M.N.A.M.Y., and M.Z.Z.; Formal analysis, M.H.H. and S.A.Z.; Writing-original draft preparation, M.H.H.; Writing—review and editing, M.N.A.M.Y. and S.A.Z.; Supervision, N.W.M.Z. and M.H.; Project administration, N.W.M.Z. All authors have read and agreed to the published version of the manuscript.

Funding: The authors would like to acknowledge the University of Malaya for the RU Grant (Project no.: GPF031A-2018).

Conflicts of Interest: The authors declare no conflict of interest.

\section{Nomenclature}

FESEM field emission scanning electron microscope

EDX energy dispersive $x$-ray spectroscopy

HFRR high frequency reciprocating rig

IL ionic liquid

NPG neopentyl glycol

PE pentaerythritol

SEM scanning electron microscope

TMP trimethylolpropane

\section{References}

1. Ismail, M.; Moghavvemi, M.; Mahlia, T.; Muttaqi, K. Effective utilization of excess energy in standalone hybrid renewable energy systems for improving comfort ability and reducing cost of energy: A review and analysis. Renew. Sustain. Energy Rev. 2015, 42, 726-734. [CrossRef]

2. Soni, S.; Agarwal, M. Lubricants from renewable energy sources-A review. Green Chem. Lett. Rev. 2014, 7, 359-382. [CrossRef] 
3. Syahir, A.; Zulkifli, N.; Masjuki, H.; Kalam, M.; Alabdulkarem, A.; Gulzar, M.; Khuong, L.; Harith, M. A review on bio-based lubricants and their applications. J. Clean. Prod. 2017, 168, 997-1016. [CrossRef]

4. Gulzar, M.; Masjuki, H.H.; Kalam, M.A.; Varman, M.; Zulkifli, N.W.M.; Mufti, R.A.; Zahid, R.; Yunus, R. Dispersion Stability and Tribological Characteristics of $\mathrm{TiO}_{2} / \mathrm{SiO}_{2}$ Nanocomposite-Enriched Biobased Lubricant. Tribol. Trans. 2016, 60, 1-11. [CrossRef]

5. Kumar, R.; Oh, J.-H.; Kim, H.-J.; Jung, J.-H.; Jung, C.-H.; Hong, W.G.; Kim, H.-J.; Park, J.-Y.; Oh, I.-K. Nanohole-Structured and Palladium-Embedded 3D Porous Graphene for Ultrahigh Hydrogen Storage and CO Oxidation Multifunctionalities. ACS Nano 2015, 9, 7343-7351. [CrossRef]

6. Kumar, R.; Singh, R.K.; Singh, D.P.; Joanni, E.; Yadav, R.M.; Moshkalev, S.A. Laser-assisted synthesis, reduction and micropatterning of graphene: Recent progress and applications. Coord. Chem. Rev. 2017, 342, 34-79. [CrossRef]

7. Hashtroudi, H.; Kumar, R.; Savu, R.; Moshkalev, S.; Kawamura, G.; Matsuda, A.; Shafiei, M. Hydrogen gas sensing properties of microwave-assisted 2D Hybrid Pd/rGO: Effect of temperature, humidity and UV illumination. Int. J. Hydrogen Energy 2021, 46, 7653-7665. [CrossRef]

8. Kumar, R.; Sahoo, S.; Joanni, E.; Singh, R.K.; Maegawa, K.; Tan, W.K.; Kawamura, G.; Kar, K.K.; Matsuda, A. Heteroatom doped graphene engineering for energy storage and conversion. Mater. Today 2020, 39, 47-65. [CrossRef]

9. Kumar, R.; Sahoo, S.; Joanni, E.; Singh, R.K.; Yadav, R.M.; Verma, R.K.; Singh, D.P.; Tan, W.K.; Del Pino, A.P.; Moshkalev, S.A.; et al. A review on synthesis of graphene, h-BN and MoS2 for energy storage applications: Recent progress and perspectives. Nano Res. 2019, 12, 2655-2694. [CrossRef]

10. Kumar, R.; Sahoo, S.; Joanni, E.; Singh, R.K.; Tan, W.K.; Kar, K.K.; Matsuda, A. Recent progress in the synthesis of graphene and derived materials for next generation electrodes of high performance lithium ion batteries. Prog. Energy Combust. Sci. 2019, 75, 100786. [CrossRef]

11. Kumar, R.; Joanni, E.; Singh, R.K.; Singh, D.P.; Moshkalev, S.A. Recent advances in the synthesis and modification of carbon-based 2D materials for application in energy conversion and storage. Prog. Energy Combust. Sci. 2018, 67, 115-157. [CrossRef]

12. Kumar, R.; Alaferdov, A.V.; Singh, R.K.; Singh, A.K.; Shah, J.; Kotnala, R.K.; Singh, K.; Suda, Y.; Moshkalev, S.A. Self-assembled nanostructures of 3D hierarchical faceted-iron oxide containing vertical carbon nanotubes on reduced graphene oxide hybrids for enhanced electromagnetic interface shielding. Compos. Part B Eng. 2019, 168, 66-76. [CrossRef]

13. Kumar, R.; Singh, R.K.; Dubey, P.K.; Kumar, P.; Tiwari, R.S.; Oh, I.-K. Pressure-dependent synthesis of high-quality few-layer graphene by plasma-enhanced arc discharge and their thermal stability. J. Nanopart. Res. 2013, 15, 1847. [CrossRef]

14. Demirtas, S.; Kaleli, H.; Khadem, M.; Kim, D.-E. Characterization of the friction and wear effects of graphene nanoparticles in oil on the ring/cylinder liner of internal combustion engine. Ind. Lubr. Tribol. 2019, 71, 642-652. [CrossRef]

15. Zulkifli, N.; Azman, S.; Kalam, A.; Masjuki, H.; Yunus, R.; Gulzar, M. Lubricity of bio-based lubricant derived from different chemically modified fatty acid methyl ester. Tribol. Int. 2016, 93, 555-562. [CrossRef]

16. Wu, D.; Xu, Y.; Yao, L.; You, T.; Hu, X. Tribological behaviour of graphene oxide sheets as lubricating additives in bio-oil. Ind. Lubr. Tribol. 2018, 70, 1396-1401. [CrossRef]

17. Zhang, G.; Xu, Y.; Xiang, X.; Zheng, G.; Zeng, X.; Li, Z.; Ren, T.; Zhang, Y. Tribological performances of highly dispersed graphene oxide derivatives in vegetable oil. Tribol. Int. 2018, 126, 39-48. [CrossRef]

18. Dou, X.; Koltonow, A.R.; He, X.; Jang, H.D.; Wang, Q.; Chung, Y.-W.; Huang, J. Self-dispersed crumpled graphene balls in oil for friction and wear reduction. Proc. Natl. Acad. Sci. USA 2016, 113, 1528-1533. [CrossRef]

19. Wu, P.; Chen, X.; Zhang, C.; Zhang, J.; Luo, J.; Zhang, J. Modified graphene as novel lubricating additive with high dispersion stability in oil. Friction 2021, 9, 143-154. [CrossRef]

20. Han, J.-S.; Choi, J.-Y.; Yoo, M.; Lee, C.-S. Synthesis, Dispersion, and Tribological Performance of Alkyl-functionalized Graphene Oxide as an Oil Lubricant Additive and Synergistic Interaction with IF-WS2. Bull. Korean Chem. Soc. 2020, 41, 518-529. [CrossRef]

21. Li, X.; Gan, C.; Han, Z.; Yan, H.; Chen, D.; Li, W.; Li, H.; Fan, X.; Li, D.; Zhu, M. High dispersivity and excellent tribological performance of titanate coupling agent modified graphene oxide in hydraulic oil. Carbon 2020, 165, 238-250. [CrossRef]

22. Sarno, M.; Cirillo, C.; Senatore, A.; Scarpa, D.; Mustafa, W.A.A. Anti-Friction and Anti-Wear Surfactant-Assisted Nano-Carbons Stable Formulations for Easy Industrialization. Tribol. Online 2021, 16, 1-15. [CrossRef]

23. Azman, S.S.N.; Zulkifli, N.W.M.; Masjuki, H.; Gulzar, M.; Zahid, R. Study of tribological properties of lubricating oil blend added with graphene nanoplatelets. J. Mater. Res. 2016, 31, 1932-1938. [CrossRef]

24. Devi, A.; Khatkar, B.S. Physicochemical, rheological and functional properties of fats and oils in relation to cookie quality: A review. J. Food Sci. Technol. 2016, 53, 3633-3641. [CrossRef]

25. Zhang, B.; Ning, W.; Zhang, J.; Qiao, X.; Zhang, J.; He, J.; Liu, C.-Y. Stable dispersions of reduced graphene oxide in ionic liquids. J. Mater. Chem. 2010, 20, 5401-5403. [CrossRef]

26. Wang, J.; Chu, H.; Li, Y. Why Single-Walled Carbon Nanotubes Can Be Dispersed in Imidazolium-Based Ionic Liquids. ACS Nano 2008, 2, 2540-2546. [CrossRef]

27. Lhermerout, R.; Diederichs, C.; Perkin, S. Are Ionic Liquids Good Boundary Lubricants? A Molecular Perspective. Lubricants 2018, 6, 9. [CrossRef]

28. Sanes, J.; Avilés, M.-D.; Saurín, N.; Espinosa, T.; Carrión, F.-J.; Bermúdez, M.-D. Synergy between graphene and ionic liquid lubricant additives. Tribol. Int. 2017, 116, 371-382. [CrossRef] 
29. Syahir, A.Z.; Zulkifli, N.W.M.; Masjuki, H.H.; Kalam, M.A.; Harith, M.H.; Yusoff, M.N.A.M.; Zulfattah, Z.M.; Jamshaid, M. Tribological Improvement Using Ionic Liquids as Additives in Synthetic and Bio-Based Lubricants for Steel-Steel Contacts. Tribol. Trans. 2019, 63, 235-250. [CrossRef]

30. Zhou, Y.; Leonard, D.N.; Guo, W.; Qu, J. Understanding Tribofilm Formation Mechanisms in Ionic Liquid Lubrication. Sci. Rep. 2017, 7, 1-8. [CrossRef]

31. Eswaraiah, V.; Sankaranarayanan, V.; Ramaprabhu, S. Graphene-Based Engine Oil Nanofluids for Tribological Applications. ACS Appl. Mater. Interfaces 2011, 3, 4221-4227. [CrossRef]

32. Berman, D.; Erdemir, A.; Sumant, A.V. Few layer graphene to reduce wear and friction on sliding steel surfaces. Carbon 2013, 54, 454-459. [CrossRef]

33. Mungse, H.P.; Kumar, N.; Khatri, O.P. Synthesis, dispersion and lubrication potential of basal plane functionalized alkylated graphene nanosheets. RSC Adv. 2015, 5, 25565-25571. [CrossRef]

34. Shebanova, O.N.; Lazor, P. Raman spectroscopic study of magnetite $\left(\mathrm{FeFe}_{2} \mathrm{O}_{4}\right)$ : A new assignment for the vibrational spectrum. $J$. Solid State Chem. 2003, 174, 424-430. [CrossRef]

35. Kumar, R.; Abdel-Galeil, M.M.; Ya, K.Z.; Fujita, K.; Tan, W.K.; Matsuda, A. Facile and fast microwave-assisted formation of reduced graphene oxide-wrapped manganese cobaltite ternary hybrids as improved supercapacitor electrode material. Appl. Surf. Sci. 2019, 481, 296-306. [CrossRef]

36. Kumar, R.; Youssry, S.M.; Soe, H.M.; Abdel-Galeil, M.M.; Kawamura, G.; Matsuda, A. Honeycomb-like open-edged reducedgraphene-oxide-enclosed transition metal oxides $\left(\mathrm{NiO} / \mathrm{Co}_{3} \mathrm{O}_{4}\right)$ as improved electrode materials for high-performance supercapacitor. J. Energy Storage 2020, 30, 101539. [CrossRef]

37. Frost, R.L.; Martens, W.; Williams, P.A.; Kloprogge, J.T. Raman and infrared spectroscopic study of the vivianite-group phosphates vivianite, baricite and bobierrite. Miner. Mag. 2002, 66, 1063-1073. [CrossRef]

38. Quinn, T.F.J. Role of oxidation in the mild wear of steel. Br. J. Appl. Phys. 1962, 13, 33-37. [CrossRef] 